\title{
The Comparative Study of Movie Narrative Strategy in Cross-cultural Perspective
}

\author{
Xin Chen \\ Foreign Language College of Shandong University of Science and Technology, Qingdao, Shandong Province, \\ China
}

Keywords: Cross-cultural perspective, the movie, the movie narrative, the comparative study.

\begin{abstract}
In the current context of economic globalization, that is cultural exchanges between different nationalities and countries in the condition of increasing frequency. Movie is the art pursue benefit maximization, Chinese filmmakers should come up with a positive attitude to face of the cross-cultural communication of the film, which makes China's commercial towards the world as much as possible. Therefore, the comparison between the two countries' commercial is very important, and one of learning each other, permeate the most obvious is the narrative strategy, actually. The article from the narrative structure, narrative emotion, three aspects of narrative discourse, Forrest Gump as example analysis of the American film narrative, and thus to the film's narrative strategy.
\end{abstract}

\section{Introduction}

As early as in silent film era, the United States Hollywood has emerged a lot of excellent movies, represented by Chaplin star is famous in the world, made outstanding contributions to the film art. It is for universal significance for the pursuit of happiness. In the $1930 \mathrm{~s}$, China has taken a farce of "lee will" and other films [1]. So far, the Chinese film not only has rich connotation and aesthetic implication, also more mature in terms of business operations. However, with the United States has formed a commercial status of different styles, subject diversification, our country's commercial movie in development at present is still in its infancy. In the current context of economic globalization, cultural exchanges between different nationalities and countries in the condition of increasing, while the film is the art pursue benefit maximization, Chinese filmmakers should come up with a positive attitude to face the cross-cultural communication of the film, make China's commercial can move towards the world as much as possible, to occupy more market. Therefore, the comparison between the two countries' commercial is very important, and one of learning each other, permeate the most obvious is the narrative strategy, actually [1]. A film in the narrative structure, emotional, and word choice directly determines the construction of film grade and sex.

\section{The film's narrative structure}

Movie narrative methods can be strange, and the film's originality is often lies in its narrative structure, the movie narrative structure mainly has two levels, a hierarchy is its internal logic, thinking, another level is the beginning of its external, development, climax and end. Narrative structure, in other words, is how the director the general framework of "telling stories", from the narrative structure and film to carry information has become, like water without source, the film is no exception. So far as that say that the effect of the part of the movie is to through the special form of expression to show up [2]. The commercial movie in the narrative structure of China and the United States has been a developing process from simple to complex; this is actually a microcosm of the development trend of movie art.

Early American movies tend to adopt single narrative, this is on the one hand, the film's technical constraints (such as the expressive force of silent film co., LTD. , the audience is often only see actors such as exaggerated body movements and facial expressions, hard to accept too complicated plot), on the other hand can also be related to the audience's thinking habit. With Chaplin directed from "City 
Lights" (City towns, 1931), for example, it's about a homeless man you fell in love with the blind flower girl story, using linear narrative in time order. First the tramps are introduced in the flower girl at first sight, and at the time of the struggling think help each other tomorrow. Then tells the tramp accidentally saved a suicidal, decide to deny people the hope of billionaire broke the tramp, tramp had to save money with a weak body to boxing, after experienced by robbers looted, rough experience of two years in prison, tramp finally help flower girl to light [2]. Audience for the fate of the homeless, but do not doubt that the final happy ending. And with the improvement of the audience to appreciate purport, the single narrative of the film had already can't meet the needs of the audience, especially the film after many narrative in the new century master after the modification experiments with multi-line, interlocking and numerous and not disorderly of narrative structure by the audience. This is period of commercial films.

The Chinese film, by contrast, is often more inclined to single narrative and linear narrative. But this kind of narrative can be divided into two kinds; one kind is story is relatively single, represented by Stephen chow series of films. One is compounding, fragmentation, represented by feng's New Year movie series of movies. With Stephen chow "Wulitou" characteristic, Lilly is directed by "flirting scholar" (1993) as an example, the film tells the Jiangnan four big wets tong pak fu maid, looks if fairy with Washington, the first of the love entanglement between Chou-hung. Tong pack fu for Chou-heung, first in Washington became assume safe, then help Washington out of spite of king Wang, finally after repeatedly break the China lady set obstacles to marry Chou-heung. Can say the film without any side outside the main line, the audience always concentrate on the tong pak fu. While feng in the movie has created a "sketch collage" narrative, influenced by writers wang shuo, his party a party b private custom and other film is largely small story, even small one from the Internet and crosstalk "burden" on a line (interpret Dream Company). In coming of ning hao, Chinese business there is obvious imitation guy Ritchie's clues, a coincidence, and small fragments of narrative. [3] "crazy car", for example, in the film difficult to make a living before the bike riders GengHao and profiteers Farah, Ferrari with his wife and two amateur killer, drug gang from Taiwan and Thailand, along with the local police several road people because all sorts of Xiamen accident in relation to each other, and because of the exciting crime involved, Ning hao on the narrative not sloppily. Little adventure, bosses anymore, etc, are driven by rapidly between drama show, and characters because of coincidence caused bad also to make the audience laugh. That runs counter to the traditional narrative structure and narrative way, both in time and space arrangement of director requirements is extremely high, which to some extent also Ning hao in the subsequent "gold heist" and "no man's land" in giving up this too complicated narrative method.

\section{The film narrative}

Film as a work of art, a message to people aesthetic pleasure is its primary purpose, but it also bring the recipient a sex from thought, ethics and moral cultivation, in order to achieve such as Horace in "odes" stressed "measure up" [3]. Especially the Chinese drama theory, "fun" is always an important content. This requires the movie must have some kind of emotion in the narrative, to let the audience can be this kind of emotion to impress, an empathy with the characters, the art of the aesthetic and utilitarian, entertaining and educational. For either China or the United States, as it were, commercial movies have to convey emotions and indoctrination of "how's sense of honor" function, but the face of the audience is different, so in the choice of emotional tendency, the expression of specific way, both sides still have certain differences.

The American film in narrative is tend to show little emotional all sorts of bad luck, incompetence, let the audience feel kind, also some of the inner desire to release. The early American emphasis on a feeling of "smile with tears", in the film on the surface of this was amused audience heavy scooped a handful of sad tears [3]. Such as "city lights" behind is absurd, and great difference between the rich and the poor social reality, hero is represented by the face hunger and poverty of the poor. In commercial stronger in the $1990 \mathrm{~s}$ and the 21st century, flay ugly task already gradually fade from the film, looking for leisure and pleasure to become film of the supreme goal. Although this period films would still be to show the dark side of society, but usually through the hero forced the "bad guys" 
unlucky to make jokes, at the same time, the little guy born and characters are also often because a twist of fate caught off guard. Such as "The Hangover" (2009) The Hangover, Doug Phil, in west Germany and Alan, four men are very ordinary middle-aged men in The United States, four people in The party in Las Vegas for drugs drunk out of a series of trivial shit, even provoke local gang members. In terms of values, the film is not according to what social problem, does not contain any critical force, the film's characters of the mistakes made by although slightly out of line, but completely accord with human nature.

\section{The narration characteristic of USA movie Forrest Gump}

Movies and other style, leave the narrative technique of cast, the film Forrest Gump with a unique narrative skill and wonderful words to deduce a classic for the audience. Film through narrative perspective, narrative space and narrative thread three aspects to narrative techniques developed to get incisively and vividly, at the same time of deepening the theme gives the film more profound artistic charm [4]. No grandiloquence in the film, but it gives each person's unique language, reflecting the different characters of different charm, shaped the vivid characters. Language is an integral part of the film, and the other art complement each other in the movie, the tone of voice, mode and thinking to embody the language of connotation of unique to depict vivid images, to express rich thought emotion, give the film a different aesthetic value.

In different words, modality and tone character unique language features. Film Forrest Gump and passers-by nurse dialogue unfolds, he told the nurses to introduce myself, the conversation very clearly embodies the communicative role of Forrest Gump as the narrator, the intent is not to get cooperation with each other [4]. Nurse for Forrest Gump is a stranger, she did not want to communicate with Forrest Gump, there is a big social distance between two people. Step into _ after reduction of tone and dialogue, the nurse just _ flavour to statement, given their own information, does not require the other party response, Forrest Gump in not invited talk with others, in the form of telling reflects Gump hope to talk with people.

Bubba and in the film Forrest Gump on duty in Vietnam jungle back when the heavy rain, bubba want at the end of the war the shrimping business, and hope to cooperate with Forrest Gump, because the two men are brothers to trouble. This paragraph of word is simple, clear thinking, of which only a “do you want to go with me to shrimp?" It is to obtain information, most of them are bubba's words, tone has stated, metaphor, and doubt, in the conversation of two people, bubba three times using modal verb "can", rather stiffly expressed his tone reservation of Forrest Gump "command", embodies the bubba shrimp self-confidence; Six times using "we" as the subject, in order to reflect bubba in the heart have decided that Forrest Gump is a good brother, he reveals their social distance is very near.

After the war, Forrest Gump met Taylor lieutenant, cynical Taylor talk the upper hand in the hotel. Taylor use interrogative sentences many times, expressed his dissatisfaction with god and reality and ridicule, embodies the spirit of veterans [4]. He asked whether Forrest Gump found god, because in his view, Forrest Gump himself as the savior, in spite of his opposition changed his fate, he should have been with honor and his soldiers died in the battle of Vietnam, it is his destiny, but Forrest Gump has lost his legs, he monster miraculously alive, at the same time also lost honor, this kind of question is his mockery of Forrest Gump, is not the real intention of questions Gump; He asked Forrest Gump can buy him a bottle of wine before go to heaven, the meaning of this sentence is the request, but Taylor revealed, in a tone of command showed he is oneself as a chief above Forrest Gump. Lt using low amounts of vulgar words showed his disdain for Forrest Gump, dissatisfaction with society and inner pain. Forrest Gump from beginning to end for let deferential reveals the social distance is far away.

In Forrest Gump, a lot of use of the spoken language, oral application which gives more flexible language characters, in order to foil atmosphere and emphasis, the film also use large amounts of the interjection and curse spell, highlights character. The character in the process of communication, communication main body is the core of the exchanges, subject to express his feelings. With multiple topics in communication, to avoid talking too drab, language can be more flexible. 
Movie Forrest Gump views of language in the film, "run" to become an important part of the hero Forrest Gump life, Forrest Gump in the "run" to realize the value of life. Forrest Gump "run" in early childhood he ran to the normal life;Adult "run" make he ran into the university, become a football star. Join the army after the "run" made him out of the danger of war, and rescued his comrades;"Run" finally ran to him hope. "Run "is" run "in the university football team, need is Forrest Gump," run "Forrest Gump even ran out of the stadium during the game, he doesn't need to know why, also don't know what rules, is just" run ", to the evaluation of Forrest Gump, coach is: he is probably the most stupid fool, but he is fast [4]. Jenny told in the film Forrest Gump: "if you are in trouble, don't f, just run, ok?Run away. "In Vietnam battlefield, Forrest Gump had ambushed and soldiers, fire surrounded them, lt let everybody "retreat", but Forrest Gump did not understand what Taylor, bubba called out to him "run" when he remembered the Jenny's words to him, then quickly ran out of the danger zone. In Forrest Gump "ran" is the "run", no other meaning, this is a non metaphorical Gump views of language.

\section{The characteristic of Chinese movie narrative}

Chinese movie also pursue a weekly narrative emotion, also can show the little helpless and personality weakness, but the domestic is more pay attention to a sense of ethics and values. As in "the gold heist," the hero small northeast of the love is a table, and he and his father, northeast JiuGuoHui narrative was one's patriotism emotion [5]. It is thriving patriotism against kwantung army forced them, seize the Japanese prepared to buy arms of gold. Such patriotism in "Hands Up" (Hands Up 2003) on the background of the Anti-Japanese War in the film but also emerge in endlessly.

If emotion reflects the film's narrative "Tao", the narrative discourse is the film "skill". In western narrative research, whether early narrative or classical narratology, after classical narratology, narrative discourse is one of the crucial aspects [5]. No matter what the director want to convey the enlightenment, hope to get the audience's psychological identification with what ultimately depends on the specific narrative discourse. Performance in the film is directed by using various connection plot splicing technique, prominent characters or psychological activities of the logo design, increase the movie artistic appeal of sound painting combination, etc. , can be regarded as the film's narrative discourse. The use of good narrative discourse can attract audience's attention; effectively arouse the audience's emotions. In this regard, the Chinese commercial movie's is much less than the equivalent us film rich variety, but with the development of the time, the Chinese director also catching up.

The early Chinese films tend to make people laugh lines to increase the effect, such as Stephen chow "Wulitou" lines and Feng Xiaogang aristocracy discourse "ridicule. However to ning hao after game full of movie clips, came to the United States film very imaginative variety of reappearance of narrative discourse, such as fast splicing, lenses declension, clever transitions, strange photography cameras, etc. Such as "steal to rob abduction" images will be cut into several parts, give the audience the performance of different characters under different space, Ning hao in "crazy stone" of this technique is very in place [5]. As mike last duel with real estate developers, screen is divided into three parts, the tense in left and right sides, the middle is a real estate producers in the office of a huge "endure" word, produce the effect of the explosive. Music is also one of the American film idiomatic narrative discourses. In the Chinese film, in learning to take advantage of this music, and change the specific music choices, such as "charlotte pains (Goodbye Mr. Loser, in 2015, is a lot of use of the time feeling extremely the pop music in the $1990 \mathrm{~s}$, on the one hand is fit "through" theme of the film, on the other hand, also for the effect of manufacturing. Such as background music Yuan hue as soon as they appear often will automatically switch to "Changjiang", this kind of weird, repeated and formulaic approach, actually happen to be in line with the barperson stressed in the meaning of "funny" laugh and the relationship between the mechanical, repetitive.

In fact, art not only means nullification, exaggeration and wacky, commercial movies doesn't mean superficial and vulgar, when the business and the combination, besides can bring endless joy to the audience, can also cause contagious ideological implication and artistic effect. If you want to achieve this, you require business pay attention to all aspects of the film art breakthrough, especially 
on the narrative art. 


\section{Summary}

At present in China and the United States still has certain difference on the narrative strategy of commercial, in general, American movies are older, more mature commercialization, regardless of whether they are "explicit" technical or "internalization" of the spirit of the kernel, is for the Chinese film offers many can draw lessons from the theory and material. The current Chinese director bold exploration, it is not difficult to find the trend of the convergence between them is more and more obvious, the gap between art and market grade of the two countries is narrowing the distance. Human pursuit of pleasure, desire for affection is universal and eternal joy, leisure culture of the broad masses of commercial movie as a kind of meat products, also will not stop the development of it, and the commercial movie in narrative technique in China and the United States, the connotation and so on various aspects of cutting is not stopping. Can be foreseen that in the future, not only Chinese audience can fully appreciate the American film, American audiences will generally get laughter from the Chinese movie.

\section{References}

[1] Y. H. Hu, the Chinese movie's narrative strategy, movie art, 2005, vol. 6, pp. 12-15.

[2] Y. L. Zhang, Film narrative strategy, Shanghai: east China normal university, 2012, vol. 5, pp. 17-19.

[3] H. B. Teng, Difference film type of China and the United States, Beijing film academy journal, 2010, vol. 10, pp. 25-27.

[4] Sh. R. Zhang, forrest gum movie narrative style, Yantai teachers college journal, 2001, vol. 2, pp. 14-16.

[5] H. B. Zhong, the narrative discourse of subversion: history and literature, contemporary writers review, 2015, vol. 2, pp. 130-132. 